\title{
Compensation for Damage to Marine Biodiversity under International Liability Regime on Vessel-Source Marine Oil Pollution Damage
}

\author{
Junhong LI \\ China University of Political Science and Law, Beijing, China
}

\begin{abstract}
Vessel-source marine oil pollution damage is governed by an international liability regime, including the CLC treaties, 2001 Bunker Convention and the 1977 Seabed Convention. Despite that "pollution damage" in these treaties does not exclude damage to marine biodiversity, the fact that damage to marine biodiversity is not mentioned in this regime arouses the question of compensability of damage to marine biodiversity under the regime. This article attempts to investigate this question from the perspectives of the relationship between marine environmental damage and damage to marine biodiversity and the possibility of compensation for damage to marine biodiversity under the regime. While the findings of this article reveal that the regime cannot provide sufficient compensation for such damage, this article in the conclusion offers some suggestions for the sake of remedying of damaged marine biodiversity under the regime.
\end{abstract}

Key words: Marine oil pollution, CLC regime, marine biodiversity damage.

\section{Introduction}

Damage to marine biodiversity can be caused by marine oil pollution resulting from ship activities such as incidents, normal ship operations and other activities like offshore operation, exploration and exploitation of mineral resources in the seabed areas, which is manifested as reduced genetic diversity ${ }^{1}$, decreased population, extinct species or change of ecosystem composition or structure ${ }^{2}$. For instance, marine species,

Corresponding author: Junhong LI, Ph.D., research fields: marine environmental law, public international law, law of the sea and tort law.

${ }^{1}$ Research has showed that reduction of genetic diversity has been found in pelagic microbial communities in Arctic seawater samples as a result of experimental exposures to crude oil or in copepod species within $30 \mathrm{~m}$ of oil platforms compared to reference sites over 3km away. See Emma L Johnston \& David A Roberts, 'Contaminants reduce the richness and evenness of marine communities: a review and meta-analysis' (2009) Environmental Pollution 157(6) 1745-1752.

${ }^{2}$ One example exhibiting the adverse effects of marine oil pollution on marine biodiversity is the 2010 Deepwater Horizon Oil Spill incident. Albeit the US trustees are still assessing potential oil spill impacts on biodiversity therein including sensitive habitats, fisheries and wildlife, the 2012 report has already showed the death of many corals at two such as fish, may be affected by marine oil pollution through direct dermal contact, ingestion via food base and inhalation, which can result in reproductive failure and other sublethal effects on fish ${ }^{3}$. Such damage may occur in the areas within and/or beyond national jurisdiction as a consequence of shipping activities. There exists no international treaty exclusively on liability and compensation for damage to marine biodiversity resulting from marine oil pollution.

hard-bottom coral communities, significant decrease of populations of resident planktivorous fish, 356 dolphin stranding in 2011 compared to a historical average of 74 with increased discovery of premature, stillborn or neonatal bottlenose dolphin stranding. See 'Natural resources damage assessment April 2012: status update for the Deepwater Horizon Oil Spill', 2012, pp35-36\&54-55, $<$ http://www.gulfspillrestoration.noaa.gov/oil-spill/affected-gul f-resources/ $>$.

${ }^{3}$ As eggs and larvae of many fish species are sensitive to oil exposure, a marine oil disaster may result in decreased spawning success, abnormal larval development, reduced growth, enlarged livers and reproductive impairment of many fish species. See ibid, pp47; Md. Shahidul Islam \& Masaru Tanaka, 'Impacts of pollution on coastal and marine ecosystems including coastal and marine fisheries and approach for management: a review and synthesis' (2004) 48 Marine Pollution Bulletin 624-649. 
Several conventions have been adopted of uniform international liability rules and procedures for marine oil pollution damage caused by such activities. Liability and compensation for vessel-source marine oil pollution damage caused by spills from oil tankers is governed by an international regime, which includes the 1969 International Convention on Civil Liability for Oil Pollution Damage (1969 Civil Liability Convention, or "1969 CLC") and the 1971 International Convention on the Establishment of an International Fund for Compensation for Oil Pollution Damage (1971 Fund Convention) that have been amended and known as 1992 Civil Liability Convention (hereinafter as "1992 CLC") and 1992 Fund Convention ${ }^{4}$ respectively, and 2003 Protocol to the 1992 Fund Convention (Supplementary Fund Protocol) $)^{5}$, altogether called as "the CLC regime" in this article. Reparation of marine oil pollution damage resulting from the escape or discharge of bunker oil from any seagoing vessel and seaborne craft is regulated by the International Convention on Civil Liability for Bunker Oil Pollution Damage $2001^{6}$ (hereinafter as “2001 Bunker Convention”). Notably, bunker pollution from oil tanker is covered by the CLC ${ }^{7}$. The 1977 Seabed Liability

\footnotetext{
${ }^{4}$ The two amended conventions came into force on 30 May 1996. The 2003 Supplementary Fund Convention entered into force in 2005. The 1971 Fund Convention ceased to be in force on 24 May 2002 and does not apply to incidents occurring after that date. The vote of the 1971 Fund Administrative Council in October 2014 announced the dissolution of the 1971 Fund with effect of 31 December 2014. See Annual Report 2014, International Oil Pollution Compensation Funds, 2015, pp37.

5 The Supplementary Fund Convention entered into force on 3 March 2005 and applies to the incidents occurring on or after that date.

6 The Bunker Convention entered into force in November 2008.

${ }^{7}$ In case of mixed oil spillage in practice, the premise of the convention indicates that it is better for the CLC to apply unless it can be clearly said that some part of the damage is applicable and separable to the Bunker Oil Convention (Article 4(1)).See Nicholas Gaskell \& Craig Forrest, 'Marine pollution damage in Australia: implementing the Bunker Oil Convention 2001 and the Supplementary Fund Protocol 2003' (2008) The University of Queensland Law Journal 27 (2)135.
}

Convention ${ }^{8}$ addresses liability and compensation for marine oil pollution damage caused by offshore activities but has not come into force yet. In the wake of the Deepwater Horizon Oil Spill ${ }^{9}$ incident and the followed Montara offshore oil platform incident ${ }^{10}$, the IMO (International Maritime Organization) has started the study of the issue on liability and compensation for transboundary pollution damage resulting from offshore oil exploitation and exploration activities ${ }^{11}$ without adopting any international legal instrument yet.

"Pollution damage" defined in these treaties has different meanings. Both the 1969 CLC and the 1977 Seabed Liability Convention regulate that "pollution damage" includes any loss or damage caused by marine

\footnotetext{
${ }^{8}$ Full name of this Convention is Convention on Civil Liability for Oil Pollution Damage Resulting from Exploration for and Exploitation of Seabed Mineral Resources. This convention, adopted in 1977, was initiated by the UK government in order to protect the marine environment of North Sea but has not yet entered into force so far.

${ }^{9}$ In April 2010, BP's Deepwater Horizon drilling rig in the Gulf of Mexico exploded and sank. Some 4.9 million barrels of oil, and an equivalent volume of gas, spewed out over three months. As one of the most productive gulf, some 1728 species feed and reproduce in the Gulf of Mexico and many were breeding at the time, exposing vulnerable larvae and young to toxic oil. According to the researchers, damage to shallow and deep ecosystems and species may last for decades, among which 6140 birds, 609 sea turtles and 100 marine mammals were dead, with only a tiny percentage washing ashore or being spotted at sea by observers. See Mellissa Gaskill, 'Deepwater Horizon: one year on', Nature, 19 April 2011.

10 The Montara oil spill occurred after a blowout and fire on the Montara wellhead platform. The blowout occurred on 21 August 2009 and the leak of gas and oil lasted 74 days before a successful intervention. Biologists said the effects of this oil spill could be catastrophic for marine ecosystems and birds, marine invertebrates, coral and marine algae. See 'Montara Oil Spill', <http://www.environment.gov.au/coasts/oilspill.html>.

${ }_{11}$ IMO Legal Committee, 97th Session, 15-19 November 2010; E.E Mitropoulos, Secretary-General of IMO, The $6^{\text {th }}$ Annual BP Shipping CEO's HSSE Forum, 24 February 2011, $<$ http://www.imo.org/mediacentre/secretarygeneral/speechesby thesecretarygeneral/pages/6th-annual-bp-shipping-ceo\%E2\%80 \%99s-hsse-forum.aspx > . At its101st Session from 28 April to 1 May 2014, the IMO Legal Committee announced the establishment of consultative group to 'develop guidance on bilateral and regional agreements or arrangement related to the liability and compensation issues connected with transboundary pollution damage resulting from offshore exploration and exploitation activities.' See http://www.imo.org/en/MediaCentre/MeetingSummaries/Legal /Pages/LEG-101.aspx, last visited on 6 ${ }^{\text {th }}$ September 2015.
} 
pollution resulting from the escape or discharge of oil, and the costs of preventive measures aiming to prevent or minimize such damage and further loss or damage caused by preventive measures ${ }^{12}$. This seemingly all-inclusive definition theoretically does not exclude damage to marine biodiversity. The 1992 CLC and the Bunker Convention specify the "pollution damage" to cover compensation for impairment of the environment but limited to the costs of reasonable reinstatement measures actually taken or to be undertaken, together with preventive measures and further damage caused by such preventive measures ${ }^{13}$. Neither treaty clarifies what reinstatement measures are and what kinds of such measures could be considered reasonable. Hence, despite that the injured environment can encompass the damaged biological components such as damage to marine biodiversity therein ${ }^{14}$, the fact that none of these treaties explicitly mention damage to marine biodiversity raises a question whether and how damaged marine biodiversity could be compensated under these conventions, the answer to which has not been explored to date.

This article will explore and discuss whether and to what extent damage to marine biodiversity could be remedied under the above-mentioned treaties on liability for marine oil pollution damage. As the CLC regime was exactly modeled by the 2001 Bunker Convention and the 1977 Seabed Liability Convention in respect of definition of "pollution damage" 15 , the CLC regime would be discussed as an example.

\section{Brief Overview of the Regimes}

The CLC regime consists of two systems, the "old" system comprising the 1969 CLC and 1971 Fund Convention and the "new" system containing the 1992 CLC, 1992 Fund Convention and 2003 Supplementary

12 The 1969 CLC, Article 1 and the 1977 Seabed Liability Convention, Article 1.6\&1.7.

${ }^{13}$ The 1992 CLC, Article I.6; Bunker Convention, Article 1.9.

14 See discussion on the relationship between marine environment and marine biodiversity in Section 3.

15 The definition of "pollution damage" in Bunker Convention follows that of 1992 CLC, while the 1977 Seabed Liability Convention modelled that of the 1969 CLC.
Protocol, all of which are in force. Under either system, the owner of a ship is strictly liable for pollution damage occurred on the territory including territorial sea of a Contracting State, resulting from the escape or discharge of oil from the ship as a result of an incident, with the 1992 CLC extending its application to cover damage in the EEZ (exclusive economic zone) or equivalent area of a Contracting State ${ }^{16}$, which means that the CLC regime does not provide liability for pollution damage occurred in the areas beyond national jurisdiction.

The CLC regime requires the owners of ships carrying more than 2,000 tons of persistent oil as cargo to maintain appropriate financial security like liability insurance, the sum of which is limited under the 1969/1992 CLC $^{17}$. The IOPC Fund (International Oil Pollution Compensation Fund) established under the 1971/1992 Fund Convention provides the second tier of limited compensation when the victim is unable to obtain full and adequate compensation for the damage under the 1969/1992 CLC because no liability arises under the CLC, the owner liable is financially incapable of meeting his obligations in full, or the damage exceeds the owner's limitation of liability ${ }^{18}$. Noting that the maximum compensation afforded by the 1992 Fund Convention might be insufficient, the 2003 Supplementary Protocol offers a third tier of limited compensation by establishing an International Oil Pollution Supplementary Fund (Supplementary Fund) that is financed in a similar way as the 1992 IPOC Fund, aiming for ensuring the victim full and

\footnotetext{
${ }^{16}$ The 1969/1992 CLC, Articles I.6, II \&III.

${ }^{17}$ The 1969/1992 CLC, Article VII. The shipowner is entitled to limit his liability to an amount that is linked to the tonnage of his ship.

18 The 1971/1992 Fund Convention, Article 4. The Fund is financed by oil receivers who received more than 150,000 tonnes of crude oil or heavy fuel oil after sea transport in a calendar year in a Fund Member State. The 1971 Fund Convention ceased to be in force on 24 May 2002. The compensation amount payable by the 1992 Fund for any one incident occurring before 1 November 2003 was limited to 135 million Special Drawing Rights (SDR), including the sum actually paid by the shipowner or his insurer, and afterwards the maximum amount payable by the 1992 Fund is limited to 203 million SDR.
} 
adequate compensation when the victim cannot get full and adequate compensation under the 1992 Fund Convention ${ }^{19}$. Hence, it can be seen that despite that the “old” system provides a two-tier compensation system and the "new" system affords a three-tier compensation system, both limit the shipowner's liability to a certain amount ${ }^{20}$, the latter of which is higher than the former.

Claims for compensation can be brought against the owner of the ship or the insurer or other person providing financial security for the owner's liability ${ }^{21}$, the IOPC Fund ${ }^{22}$ or the IOPC Supplementary Fund ${ }^{23}$ in accordance with relevant treaties. The claimants, whether a Member State or individuals, will lose the right of compensation unless an action is brought within three years from the date when the damage occurred and no claims will be admissible after six years from the date of incident which caused the damage ${ }^{24}$. Both systems exempt the shipowner from liability when he proves that the damage resulted from force majeure such as an act of war or civil war, act of God like a natural disaster, was wholly caused by a third party intentionally or negligently or by the negligence or other wrongful act of any Government or other authority "responsible for the maintenance of lights or other navigational aids in the exercise of that function"25.

\section{Damage to Marine Biodiversity vs. Environmental Damage Caused by Marine Oil Pollution}

Although scientists acknowledge that marine biodiversity is not well understood, research shows that

\footnotetext{
19 The 2003 Supplementary Protocol, Article 4. The maximum amount payable for one incident under the Supplementary Fund is limited to 750 million SDR, including the amount payable under the 1992 Conventions.

${ }^{20}$ The owner is not entitled to limit his liability if the pollution damage occurred as a result of his personal act or omission, the intent to cause the damage or recklessly with knowledge that such damage would probably result. The 1969/1992 CLC, Article V.2.

${ }^{21}$ The 1969/1992 CLC, Article VII.8.

22 The 1971/1992 Fund Convention, Article 4.

${ }^{23}$ The 2003 Supplementary Fund Protocol, Article 4.

${ }^{24}$ The 1969/1992 CLC, Article VIII; the 1971/1992 Fund Convention, Article 6.

${ }^{25}$ The 1969/1992 CLC, Article III.2.
}

marine environment enjoys more biodiversity than its terrestrial and freshwater counterparts ${ }^{26}$. The question is: what is the relationship between marine environment and marine biodiversity? This needs the analysis of the concept of "marine environment".

According to the definition of "environment" provided by the Lugano Convention ${ }^{27}$, environment encompasses "natural resources both abiotic and biotic, such as air, water, soil, fauna and flora and the interaction between the same factors", which explicitly indicates that "environment" contains diverse natural biological resources and the ecological complexes. The only legal definition of "marine environment" found in the international legal instruments is in the Regulations on Prospecting and Exploration for Polymetallic Nodules in the Area ("ISA Regulations"), which states that "marine environment" includes "the physical, chemical, geological and biological components, conditions and factors which interact and determine the productivity, state, condition and quality of the marine ecosystem, the waters of the seas and oceans and the airspace above those waters, as well as the seabed and ocean floor and subsoil thereof” ${ }^{28}$. This definition demonstrates that the marine environment encompasses non-living and living resources, marine ecosystems and the ecological complexes, including diverse marine life. Such conclusion can be proven through the definition of "pollution of the marine environment” in the $\mathrm{UNCLOS}^{29}$, which indirectly

\footnotetext{
${ }^{26}$ Robert M. May and J. Godfrey, 'Biological diversity: differences between land and sea [and discussion]' (1994) Philosophical Transactions: Biological Sciences 343(1303) 108; Elliot A. Norse \& Larry B. Crowder, Marine conservation biology: the science of maintaining the sea's biodiversity (Island Press 2005); Enric Sala \& Nancy Knowlton, 'Global marine biodiversity trends’, (2006) 31 Annual Review Environmental Resources 93-122.

${ }^{27}$ Lugano Convention on Civil Liability for Damage Resulting from Activities Dangerous to the Environment, Article 2.10.

${ }^{28}$ Regulations on Prospecting and Exploration for Polymetallic Nodules in the Area, Regulation 1.3 (c).

${ }_{29}$ UNCLOS, Article 1.1(4). "Pollution of the marine environment" is defined in the UNCLOS as "the introduction by man, directly or indirectly, of substances or energy into the marine environment, including estuaries, which results or is likely to result in such deleterious effects as harm to living resources and marine life...”
} 
notes that marine life and living resources are included in the marine environment. In consistence with the definition of "biodiversity" in the Convention on Biological Diversity ${ }^{30}$ and the concept of "marine environment" in Chapter 17 of Agenda $21^{31}$, it can be drawn upon that marine environment, including coastal and oceanic areas, encompasses various marine life in coastal and oceanic ecosystems and thus marine biodiversity therein.

"Environmental damage" defined in the report of UNEP on Liability and Compensation for Environmental Damage arising from Military Activities in 1996 refers to a measurable adverse change to the quality of the environment per se or any of its components, "including its use and non-use values and its ability to support and sustain an acceptable quality life and a viable ecological balance" ${ }^{32}$. There is no legal definition of damage to marine environment. The ISA

\footnotetext{
30 Article 2 of the Convention defines "biodiversity" as "the variability among living organisms from all sources, including, 'inter alia', terrestrial, marine, and other aquatic ecosystems, and the ecological complexes of which they are part: this includes diversity within species, between species and of ecosystems".

31 "Marine environment" in 17.1 of Chapter 17 in Agenda 21 covers "the oceans and all seas and adjacent coastal areas". In fact, "marine biodiversity" in many scientific documents and legal articles also includes marine and coastal biodiversity. See John S. Gary, 'Marine biodiversity: patterns, threats and conservation needs', (1997) 6 Biodiversity and Conservation 153-175; Boyce Thorne-Miller, The living ocean: understanding and protecting marine biodiversity $\left(2^{\text {nd }}\right.$ ed., Island Press 1999); Carlos M. Duarte, 'Marine biodiversity and ecosystem services: an elusive link (2000) 250 Journal of Experimental Marine Biology and Ecology 117-31; Robin Kudis Craig, 'Protecting international marine biodiversity: international treaties and national systems of marine protected areas'(2005) Journal of Land Use\& Environmental Law 20(2) 333-370.

${ }^{32}$ UNEP, Report of the Working Group of Experts on Liability and Compensation for Environmental Damage arising from Military Activities (UNEP 1996) para.45; or Julio Barboza, 'The ILC and Environmental Damage' in Peter Wetterstein (ed.), Harm to the Environment: The right to compensation and the assessment of damages (Clarendon Press: Oxford, 1997) 76. Barboza also indicated that environmental damage shall include the damage to the components of the environment "as well as the loss or diminution of environmental values caused by the deterioration or destruction of such components".
}

Regulations ${ }^{33}$ provides the concept of "serious harm to the marine environment", which means an effect from activities in the Area on the marine environment that "represents a significant adverse change in the marine environment determined" according to the rules, regulations and procedures adopted by the Authority based on internationally standards and practices.

From the above-mentioned legal definitions, it can be concluded that damage to environment or environmental damage may cover injury to biological element of the environment such as various marine living organisms, diverse genes within such species and ecosystems of which such organisms are part of, that is, the components of biodiversity. This is reflected in the definition of "environmental damage" in the European Council Environmental Liability Directive (ELD), which includes damage to protected species and natural habitats ${ }^{34}$. It is in this sense that damage to biodiversity was ever considered as a sub-category of damage to the environment ${ }^{35}$.

Marine environmental damage and damage to marine biodiversity have some points in common: both marine environment and marine biodiversity can be seriously affected by some activities such as accidents, activities that may result in the release of large scale of oil spill, chemical or toxic pollutants, or hazardous or dangerous activities to the environment; both need long time to recover and some chronic damage may take

\footnotetext{
33 It refers to Regulations on Prospecting and Exploration for Polymetallic Nodules in the Area adopted by the International Seabed Authority, Regulation 1.3(f).This only applies to prevention instead of liability. See Louise De La Fayette, 'The concept of environmental damage in international liability regimes' in Michael Bowman \& Alan Boyle (eds.), Environmental damage in international and comparative law: problems of definition and valuation (Oxford University Press, 2002) 150. Meanwhile, although the ISA Regulations prescribes that the contractor shall be liable in particular for damage to marine environment after the completion of the exploration phase (Regulation 30), the Regulations is mainly for the prospecting and exploration of polymetallic nodules, instead of the protection of deep seabed marine environment.

${ }^{34}$ ELD, Article 2. The full name of the ELD is Directive 2004/35/EC of the European Parliament and of the Council of 21 April 2004 on environmental liability with regard to the prevention and remedying of environmental damage (ELD), available at ec.europa.eu.

${ }^{35} \mathrm{UNEP} / \mathrm{CBD} / \mathrm{BS} / \mathrm{TEG}-\mathrm{L} \& \mathrm{R} / 1 / 3,2004$, para.24.
} 
longer time to be exposed; neither is easy to be assessed or compensated.

However, damage to marine environment does not necessarily cover loss of the variation within species, between species and of ecosystems. For instance, marine pollution may cause damage to the marine environment but might only result in the reduction of the number of marine species that could recover naturally within a period of time. Different from environmental damage, damage to marine biodiversity such as damage to highly endemic species or unique ecosystems may be irreversible, and damage to genetic diversity may be not easy to be detected ${ }^{36}$.

\section{Damage to Marine Biodiversity that Can Be Compensated under the Regime}

Although theoretically pollution damage defined in the 1969 CLC and the 1977 Seabed Liability Convention may cover damage to marine biodiversity, in practice it does not mean that the injured marine biodiversity is compensable under these treaties. In Antonio Gramsci case, the USSR submitted a claim for damage to the marine environment per se caused by an oil spill incident, but was declined by the IOPC Fund which took the position that claims for non-economic environmental damage or based on abstract quantification of damage calculated according to theoretical models should not be accepted $^{37}$. This was followed by several other cases ${ }^{38}$, which revealed the fact that damage to marine environment per se or damage to marine biodiversity is not compensable under either convention.

Both the 1992 CLC and the 2001 Bunker Convention clarify that compensation for damaged marine environment is confined to the costs of reasonable

\footnotetext{
36 See supra notes $1-3$.

37 71FUND/A/ES.1/13, para.11(a) and Annex I.

For instance, Antonio Gramsci incident case,71FUND/EXC.2/4, paras 7.1-7.14, 71FUND/EXC.20/6, para 3.3.3; Haven incident case, 71FUND/EXC.40/4, section 7, 71FUND/EXC.43/2/1, section 3\&4, 71FUND/EXC.48/4, para 2.2.1, 71FUND/EXC.61/2; Seki incident case, 71FUND/EXC.47/6, section 9; Nissos Amorgos incident, 71FUND/EXC.55/9/Add.1, paras 6.1-6.4; Volgoneft 139 incident case, 92FUND/EXC.41/8, paras 7.1,7.4\&9.2.
}

reinstatement measures and costs of preventive measures. Damage to marine biodiversity potentially falls under this definition depending on whether "reasonable" reinstatement measures include measures to reinstate the injured marine biodiversity. The criteria established by the Fund Assembly for reimbursing the costs of reinstatement measures in its Claims Manual/2013 interpret that "reasonable” reinstatement measures should be likely to significantly accelerate the natural recovery process of damaged environment, and should not, "as far as possible", result in the degradation of other habitats or in adverse consequences for other natural or economic resources ${ }^{39}$. Nevertheless, because of the non-legally binding nature of the Claims Manual, these criteria are only instructional.

What kind of damage to marine biodiversity is compensable in practice under the CLC regime then? In the case of the Braer incident, the 1971 Fund Executive Committee decided that costs of cleaning up contaminated birds and other animals incurred by voluntary groups for the protection of wildlife could get reimbursed provided that such measures were carried out efficiently and were useful to mitigating the impact on such animals ${ }^{40}$. The Committee also admitted claims for costs of clean-up of oiled wildlife in Erika incident case $^{41}$. It can be concluded that clean-up of oiled or

\footnotetext{
39 The criteria established by the Fund Assembly for compensating the costs of reinstatement measures in its Claims Manual 2013 are as follows: (1) the measures should be likely to accelerate significantly the natural process of recovery; (2) the measures should seek to prevent further damage as a result of the incident; (3) the measures should, as far as possible, not result in the degradation of other habitats or in adverse consequences for other natural or economic resources; (4) measures should be technically feasible; (5) costs of the measures should not be out of proportion to the extent and duration of the damage and the benefits likely to be achieved. See IOPC Fund Claims Manual 2013 (IOPC Fund, 2013) pp39, para.3.6.5. This most updated Manual is exactly the same as its 2008 version in respect of such expression. See IOPC Fund Claims Manual 2008, pp36, para.3.6.5.

$40 \quad$ 71FUND/EXC.34/5/Add.1,Paras

4.8.1-4.8.3; 71FUND/EXC.34/9, Para 3.3.28.

41 In the Erika incident case, the 1992 Fund Executive Committee noted that the organization for the protection of birds had been compensated for the costs of cleaning oiled birds by the French Government, TotalFinaElf and private
} 
contaminated wildlife, birds or other marine animals as a result of an oil incident could be compensated under the CLC regime.

The Erika incident case further revealed that should the causation link be established between the alleged loss and the pollution resulting from the incident, costs for restoration of damaged habitats may get reimbursed under the 1992 CLC and 1992 Fund Convention ${ }^{42}$. Although costs for reinstatement of damaged ecosystems or habitats have never been compensated in practice so far, definition of "pollution damage" in the CLC regime does not exclude such damage should the restoration of damaged marine biodiversity be calculated in monetary terms instead of basing on abstract model. Thus theoretically damage to components of marine biodiversity such as injured habitats or damaged species should fall within the application of the CLC regime ${ }^{43}$. Under whichever

donors. For such reason, the claim was rejected. See 92FUND/EXC.29/3, paras. 9.3.4-9.3.6.

42 In this case, a salt producers' union submitted a claim relating to advance payments made by the union for the costs of restoration of salt marshes in 2001 which has allegedly become necessary as a result of the incident. This claim was rejected because of lacking a sufficient link of causation between the proliferation of harmful animals and plants and the pollution resulting from the incident. See 92FUND/EXC.32.3, paras 13.3.9-13.3.11.

${ }^{43}$ However, due to the fear of a huge amount of claims for environmental damage from governments, environmental organizations and individuals, the Fund insisted that the Fund would not pay anything for compensation to the marine environment per se, which was reflected in the 1991 Haven case and the 2008 Volgoneft case. In the former case, the Italian government claimed compensation for damage to marine environment per se and was allowed by the Italian courts. This case was finally concluded by the agreement between the Fund and the Italian government. For details, see Report on the Activities of the International Oil Pollution Compensation Fund in the Calendar Year 1994 (IOPC Funds 1994)36-39. For a report on the settlement, see IOPC Funds, Annual Report 1999, pp42-48. Concerning the latter case, at a meeting in May 2008 the Russian authorities informed the 1992 Fund that the Ministry of Natural Resources had submitted a claim for environmental damage for some RUB 6048.6 million (£133 million). The Secretariat informed the Russian authorities that this claim was not admissible as it was based on an abstract quantification of damages calculated in accordance with a theoretical model. The final decision in April 2011 by the Supreme Court held that the shipowner's limitation fund was 3 million SDR. See Report on the Activities of the International Oil Pollution Compensation Funds in 2011, (International Oil Pollution Compensation Funds, 2011)26-31. circumstance, damage to marine biodiversity should be assessable and quantifiable so as to be applied by the CLC regime. Moreover, costs for some post-spill studies such as studies on monitoring subsequent clean-up operations could be reimbursed in some cases like Sea Prince incident case and Nissos Amorgos incident case $^{44}$. In Nissos Amorgos incident case, however, claims for scientific studies of shellfish, mangroves and migratory birds were regarded inadmissible ${ }^{45}$

Under these treaties, preventive measures can be taken anywhere in order to prevent or minimize the loss or damage caused by an incident. In Kihnu incident case $^{46}$, preventive measures taken by a State party within territorial waters of a non-party State were covered by the CLC regime provided these measures were taken to prevent or minimize pollution damage within the territory of the State party. In principle, the same rule shall be applied to the preventive measures taken on the high seas. Concerning damage to marine biodiversity, preventive measures may comprise clean-up operations such as cleaning up contaminated species and measures to protect resources vulnerable to oil such as sensitive coastal habitats. Removing any remaining persistent oil from a sunken ship at reasonable costs with minimal risk of causing further pollution would be refunded, which may help mitigate the direct harm and the potential gradual damage to biodiversity in the deep seabed area. To prevent further harm to species on the seabed affected by an oil spill incident, it is necessary to clean up the oil in this area and costs for taking such measures could be

\footnotetext{
${ }^{44}$ SeaPrince incident case, 71FUND/EXC.59/6; Nissos Amorgos incident case, 71FUND/EXC.60/10, paras 2.9-2.12\&9.1-9.5. Along with the dissolution of the 1971 Fund, the Nissos Amorgos case was closed with the P\&I Club paying $£ 4000$ to the 1971 Fund. See AnnualReport 2014, International Oil Pollution Compensation Funds, 2015, pp37

45 71FUND/EXC.60/17, paras 3.9.12-3.9.15.

46 In June 1996 the 1971 Fund Executive Committee decided that the preventive measures taken by the Finnish authorities within the territorial waters of Estonia (a non-Member State) fell within the scope of application of the Civil Liability and Fund Conventions. See 71FUND/EXC.49/5, 71FUND/EXC.49/12, para 3.4.6.
} 
reimbursed $^{47}$.

\section{Damage to Marine Biodiversity that Cannot Get Compensated under the Regime}

Compensation for damaged marine biodiversity other than the clean-up of oiled wildlife or affected site has not been practised. As all these treaties but the 1969 CLC are applicable to pollution damage caused in the territorial sea and the EEZ ${ }^{48}$, damage to marine biodiversity suffered in the areas beyond national jurisdiction or in the territory of a non-party State is not compensable under these conventions. Moreover, damage to marine biodiversity resulting from marine oil pollution resulting from war, hostilities, insurrection or a natural disaster cannot get compensated under these treaties ${ }^{49}$. The same rule applies to the damage caused by oil escaped or discharged from a warship or other State-owned or operated ship on Government non-commercial service at the time of the incident ${ }^{50}$.

Under the 1992 CLC and the 2001 Bunker Convention, damage to marine biodiversity might be compensable only when the reinstatement measures have been taken or are to be undertaken. It may happen that a seriously damaged habitat or extinct species could not be reinstated to the baseline condition, in which case it may be impossible to take restoration

\footnotetext{
${ }^{47}$ As the oiled seabed is not visible, to what extent the affected area could be cleaned so as to effectively prevent the further harm to the species therein may need further scientific study of the affected site as in the Deepwater Horizon Incident. Effective clean-up of the affected area may be considered a part of restoration measures. Preventive measures could be utilized as an emergency response to mitigate the damage and prevent further harm to a certain extent.

48 The 1977 Seabed Liability Convention may also be applied to continental shelf, where a coastal State has sovereignty over natural resources. See Article 2(b) of the Convention: “...in the areas in which, in accordance with international law, it has sovereign rights over natural resources”. The 1969 CLC only applies to the territorial sea of a State party (Article 2).

49 The 1969 CLC, Article III.2(a); the 1992 CLC, Article III.2(a); the 2001 Bunker Convention, Article 3.3; the 1977 Seabed Liability Convention, Article 3.3.

50 The 1969 CLC, Article XI; the 1992 CLC, Article XI; the 1992 Fund Convention, Article 4.2; the 2001 Bunker Convention, Article 4.2.
}

measure and hence such damage could not be recovered under the conventions. Moreover, as the CLC regime, the 2001 Bunker Convention and the 1977 Seabed Liability Convention all apply to pollution damage resulting from an incident, gradual damage to marine biodiversity caused by operational marine oil pollution is not covered by these treaties. Damage to marine biodiversity caused by an incident would not be compensated after three years from the date when the damage occurred or six years from the date of the incident which caused the damage ${ }^{51}$. Neither the CLC regime nor the Bunker Convention is applicable to such damage caused by marine pollution resulting from offshore activities.

\section{Damage to Marine Biodiversity outside the Regime}

Although damage to marine biodiversity caused by marine oil pollution under the CLC regime is only compensable in terms of the return of costs for clean-up of contaminated sites and oiled wildlife in practice, damage to marine biodiversity or at least injury to marine species and habitats may be remedied in accordance with national law in some countries. In Patmos incident case, for instance, the Court of Appeal had granted the State of Italy compensation concerning the loss of a certain quantity of fish and damage to plankton and benthos as a result of the pollution ${ }^{52}$. In Erika incident case, the Court of Appeal according to French law in its judgement accepted the right to compensation for damage to non-marketable environmental resources ${ }^{53}$, which may cover damage to functional species, ecosystem or habitats that cannot be evaluated in terms of monetary value.

These national practices showed that damage to marine biodiversity or at least damage to components of marine biodiversity can be compensated. Actually,

\footnotetext{
${ }^{51}$ The 1992 CLC, Article VIII.

${ }^{52}$ 71FUND/EXC.38/2, paras 3.2.9-3.2.11; 71FUND/EXC.38/9, paras 3.1.1-3.1. 4.

53 IOPC Funds, Incidents involving the IOPC Funds 2011 (IOPC Funds 2011) 10-11.
} 
besides that damage to non-marketable value of marine resources is compensable as in the Erika Incident case, claims for damage to natural resources based on abstract theoretical model are acceptable under the US law ${ }^{54}$, which implies that damage to marine biodiversity caused by marine pollution could be assessable and compensable. Since the "pollution damage" defined in these treaties does not itself exclude damage to marine biodiversity, it is indispensable to make modifications of these conventions to compensate such damage in practice ${ }^{55}$.

\section{Suggestions}

As "pollution damage" in the treaties on marine oil pollution damage does not exclude damage to marine biodiversity, compensation for damage to marine biodiversity under the 1992 CLC and 2001 Bunker Convention may be achieved through the return of the costs for preventive measures after the incident and the costs for reasonable reinstatement measures taken or to be undertaken. Whilst preventive measures may encompass the removal of pollutants from contaminated sites or oiled species to prevent further damage, no treaty on marine oil pollution damage defines reasonable reinstatement measures, which leaves the remedying of damage to marine biodiversity a pending question under the regime.

The practice revealed that only damage to part of components of marine biodiversity within the territorial sea and EEZ of a State Party, specifically the costs for clean-up of contaminated sites and oiled wildlife and/or possibly the damaged habitats, is compensable under the CLC regime. This can result in inadequate compensation for damage to marine biodiversity under the regime. For instance, in a heavily polluted marine site, only removing pollutants is not likely for the affected marine species or habitats

\footnotetext{
54 The US Department of Interior developed two kinds of procedures for the assessment of damage to natural resources, in which Type A procedure incorporates two computer models. See CERCLA 42 U.S.C.A. §9651(c)(2).

${ }^{55}$ For the possible modifications, see section 7 'suggestions' below.
}

to recover naturally within a period of time, in which case further intervention measures are needed such as restoration measures for the sake of restoring the injured marine biodiversity to its baseline condition ${ }^{56}$. Moreover, as not all injury to marine biodiversity such as the non-use value of marine biodiversity could be calculated in monetary term ${ }^{57}$, to achieve the objective of these treaties of providing "adequate compensation" for the impaired environment including the injured marine biodiversity ${ }^{58}$, it is necessary to adopt other methods for the measurement of damage to natural resources as used in the US regulations and the ecosystem service approach for the restoration of the injured marine biodiversity. Furthermore, the same oil pollution incident may affect both the area within national jurisdiction and the high sea area, or the species ranging from the EEZ of a State party and the high seas, which requires that compensation for injury to such species or biodiversity in the high sea shall be taken into account.

This needs the establishment of explicit liability for damage to environment per se or damage to marine biodiversity. To this end, the definition of "pollution damage" under these treaties shall be changed or expanded to cover damage to marine biodiversity and the diminution in the values of services unpinned by marine biodiversity, the compensation for which shall encompass, more than "costs of reasonable measures of reinstatement actually undertaken or to be undertaken"

\footnotetext{
56 This is reflected in some cases such as Exxon Valdez case and Deepwater Horizon Oil Spill case. In both cases, restoration plan and further measures were adopted in order to remediate the contaminated environment and natural resources therein. See Exxon Valdez oil spill restoration plan (Exxon Valdez Oil Spill, Trustee Council, November 1994, pp13) $<$ http://www.evostc.state.ak.us/facts/restorationplan.cfm>; for Deepwater Horizon Oil Spill case, see supra note 2.

57 For the discussion of economic valuation of marine biodiversity, see Nicola Beaumont, et al, Marine Biodiversity: An Economic Valuation (Defra UK report 2006); WWF, The value of our ocean: the economic benefits of marine biodiversity and healthy ecosystems (WWF 2008).

${ }^{58}$ For example, the 1992 CLC was adopted for "determining questions of liability and providing adequate compensation" (preamble, para.3), which was followed by the 2001 Bunker Convention.
} 
and costs of preventive measures and further loss or damage caused by preventive measures ${ }^{59}$, the reparation of the injured marine biodiversity and services through the restoration, rehabilitation, replacement, or acquisition approaches, the interim loss during the recovery period and the reimbursement of reasonable costs for assessing such damage and services. From the practical experience under the CLC regime, the possible obstacles to such changes may include the lack of State will, shortage of clear damage assessment standards and compensable value characteristics ${ }^{60}$ as well as opposition from tanker owners ${ }^{61}$.

Regarding the issue of lacking State will ${ }^{62}$, it should be noted that not all Parties to the 1969/1992 CLC opposed to compensation for damage to environment per se or damage to natural resources, as is seen in the Erika case ${ }^{63}$. Moreover, as most parties to the CLC regime are parties to the UNCLOS, these countries are obliged to protect the marine environment and develop a liability regime for damage to the marine

\footnotetext{
${ }^{59}$ The 1992 CLC, Article I.6.

${ }^{60}$ G. Little \& J. Hamilton, 'Compensation for catastrophic oil spills: a transatlantic comparison’ (1997) Lloyd's Maritime and Commercial Law Quarterly, pp68.

${ }^{61}$ For example, the International Tanker Owners Pollution Federation Limited had noted that the introduction of new species into an area could pose ecological risks and interrupt natural recovery processes. See Third Intersessional Working Group, Admissibility for claims under environmental damage under the 1992 civil liability and fund conventions: submission by the International Tanker Owners Pollution Federation limited (92FUND/WGR.3/5/2, London: IOPC Fund 1992, 2001).

62 Some States with significant shipping and oil receiving interests such as Japan and Korean opposed the revision of environmental reinstatement criteria because of the fear of potential large quantity of environmental damage claims. See International Oil Pollution Compensation Fund 1992, Record of decisions of the sixth session of the assembly (92FUND/A.6/28, London: IOPC Fund 1992, 2001).

${ }^{63}$ In this case, the French government, supported by Italy, proposed to amend the conventions to allow member states to permit claims for the introduction of identical or equivalent ecological attributes in an adjacent marine area, borrowing the provisions of the US OPA 1990. The European Commission also added political pressure in 2000 on the international oil pollution liability system and called for the amendment of the 1992 CLC to enable restorative compensation for damage to the environment per se. See H. Ringbom, The Erika accident and its effects on EU maritime regulation Maritime Safety Unit (Directorate general for energy and transport, European Commission, Brussels, 2001).
}

environment caused by marine pollution ${ }^{64}$, failing of which will result in responsibility of these countries ${ }^{65}$. Further, along with the entry-into-force of the ELD, Member States of the European Union have established a liability regime for damage to protected species and natural habitats and water damage at national level ${ }^{66}$. Although the ELD excludes its application to such damage caused by marine oil pollution governed by the CLC regime or the 2001 Bunker Convention ${ }^{67}$, the fact that the injured protected species or natural habitats under the current CLC regime cannot be recovered may hamper the efforts of the States to protect these species and natural habitats and weaken the effects of the ELD regime, which might make the Member State Parties to the CLC conventions expedite their request for the compensation of damaged species or natural habitats under the CLC regime. Actually, the Parties to the 1992 CLC conventions have been making efforts on this issue: despite of its guidance nature, the most recent IOPC Claims Manual 2013 clarifies that costs of reasonable reinstatement measures for accelerating natural recovery of environmental damage including the costs for relevant post-spill studies on assessment of such damage could be claimed for compensation ${ }^{68}$. Compared with the rigid interpretation of the concept

\footnotetext{
${ }^{64}$ The UNLCOS, Part XII.

65 Arguably, no State parties have been held liable for the breach of these obligations but the general "no-harm" rule has been accepted globally, which means that a State shall ensure the activity of its nationals or in the area within national jurisdiction not to cause damage to environment of another State or the area beyond national jurisdiction.

${ }^{66}$ The transposition of the ELD by the Member States of the European Union was finally completed by July 2010.

${ }^{67}$ The ELD, Annex IV. The EU itself adopted legislation on marine pollution but none is on the liability for environmental damage. See European Commission, 'Legislation', $<$ http://ec.europa.eu/echo/policies/marine_pollution/legislation en.htm>.

${ }^{68}$ The IOPC Fund, Claims Manual 2013, para.1.4.11 \& 3.6.3, 3.6.4, pp13\&39. Reinstatement measures for enhancing the natural recovery of the damaged components of the environment include "(R)einstatement measures taken at some distance from, but still within the general vicinity of, the damaged area may be acceptable, so long as it can be demonstrated that they would actually enhance the recovery of the damaged components of the environment." (para.3.6.4, pp39).
} 
of "pollution damage" under this regime ${ }^{69}$, this seemingly small forward step needs to be granted legally binding effect.

\section{Acknowledgment}

The author would like to thank Professor Michael
Tsimplis for his invaluable suggestion and advice on the draft of this article. Appreciation also goes to Professor Vehbi S Ataergin who reviewed and advised the later revision of the article. The author acknowledges China-UK Scholarship for Excellence Program for their support in this research.
69 The most recent interpretation of the 1992 CLC conventions can be seen in The international regime for compensation for oil pollution damage: explanatory note prepared by the Secretariat of the International Oil Pollution Compensation Funds, in which "pollution damage" is interpreted in terms of environmental damage to be restricted to costs actually incurred or to be incurred for reasonable measures to reinstate the contaminated environment. See The international regime for compensation for oil pollution damage: explanatory note prepared by the Secretariat of the International Oil Pollution Compensation Funds (Secretariat of the International Oil Pollution Compensation Funds, 2011, pp3). 